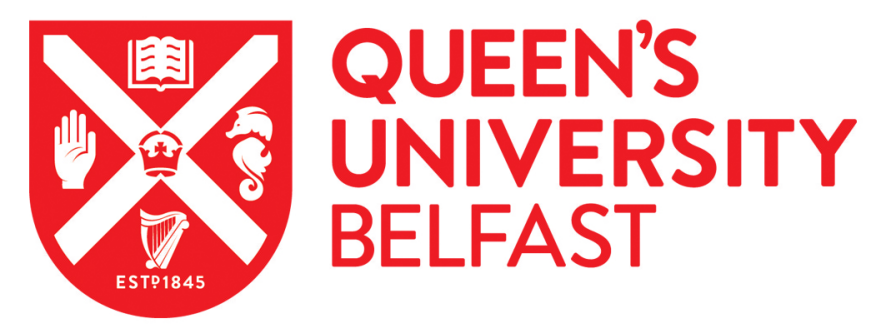

\title{
Influence of preoperative femoral orientation on radiographic measures of femoral head height in total hip replacement
}

O'Connor, J. D., Hill, J. C., Beverland, D. E., Dunne, N. J., \& Lennon, A. B. (2021). Influence of preoperative femoral orientation on radiographic measures of femoral head height in total hip replacement. Clinical Biomechanics, 81, [105247]. https://doi.org/10.1016/j.clinbiomech.2020.105247

Published in:

Clinical Biomechanics

Document Version:

Peer reviewed version

Queen's University Belfast - Research Portal:

Link to publication record in Queen's University Belfast Research Portal

Publisher rights

(C) 2020 Elsevier Ltd. All rights reserved.

This manuscript is distributed under a Creative Commons Attribution-NonCommercial-NoDerivs License

(https://creativecommons.org/licenses/by-nc-nd/4.0/), which permits distribution and reproduction for non-commercial purposes, provided the author and source are cited.

\section{General rights}

Copyright for the publications made accessible via the Queen's University Belfast Research Portal is retained by the author(s) and / or other copyright owners and it is a condition of accessing these publications that users recognise and abide by the legal requirements associated with these rights.

Take down policy

The Research Portal is Queen's institutional repository that provides access to Queen's research output. Every effort has been made to ensure that content in the Research Portal does not infringe any person's rights, or applicable UK laws. If you discover content in the Research Portal that you believe breaches copyright or violates any law, please contact openaccess@qub.ac.uk. 


\section{Highlights}

- Little focus on femoral head height in total hip arthroplasty

- Relative reliability of radiographic landmark references unknown

- This simulation study modelled different femoral orientations

- Error shown to be common and greater trochanter more sensitive to rotation 
Influence of Preoperative Femoral Orientation on Radiographic Measures of Femoral Head

a School of Mechanical and Aerospace Engineering, Queen's University Belfast, UK,

${ }^{\mathrm{b}}$ Primary Joint Unit, Musgrave Park Hospital, Belfast, UK,

${ }^{\mathrm{c}}$ School of Mechanical and Manufacturing Engineering, Dublin City University, Dublin 9, Ireland.

${ }^{\mathrm{d}}$ Centre for Medical Engineering Research, School of Mechanical and Manufacturing Engineering, Dublin City University, Dublin 9, Ireland.

${ }^{\text {e }}$ School of Pharmacy, Queen's University Belfast, Belfast, United Kingdom.

$11 \quad{ }^{\mathrm{f}}$ Department of Mechanical and Manufacturing Engineering, School of Engineering, Trinity College Dublin, Dublin 2, Ireland.

13 g Advanced Manufacturing Research Centre (I-Form), School of Mechanical and Manufacturing Engineering, Dublin City University, Glasnevin, Dublin 9, Ireland

${ }^{\mathrm{h}}$ Advanced Materials and Bioengineering Research Centre (AMBER), Royal College of Surgeons in Ireland and Trinity College Dublin, Dublin, Ireland.

$17 \quad{ }^{\text {i }}$ Advanced Processing Technology Research Centre, Dublin City University, Dublin 9, Ireland.

$18 \quad \mathrm{j}$ Trinity Centre for Biomedical Engineering, Trinity Biomedical Sciences Institute, Trinity College Dublin, Dublin 2, Ireland.

Corresponding author:

Word count (abstract): 244

Word count (main text): 2621
Dr Alex Lennon

School of Mechanical and Aerospace Engineering

Queen's University Belfast, BT9 5AH

United Kingdom

Email: a.lennon@qub.ac.uk 


\section{ABSTRACT}

\section{Background}

32 In total hip arthroplasty the surgeon aims to restore the biomechanics of the joint. Femoral height has

33 the greatest influence on restoring limb length and contributes equally to the restoration of femoral

34 head centre. On X-ray, the level of femoral neck resection is most often referenced off the upper

35 border of lesser trochanter. Less frequently, femoral head centre is referenced from the tip of the

36 greater trochanter. The error in measurement of femoral height resulting from unknown femoral

37 rotation is crucially important and can result in inappropriate surgical planning for implant selection

38 and placement. It is unknown which reference produces lower error.

\section{Methods}

40 A sample of femoral shapes was generated using a femoral statistical shape model. These were

41 placed in a range of orientations in terms of external rotation and flexion, at intervals of $10^{\circ}$.

42 Simulated X-rays were then produced and the distances from the tip of either greater or lesser

43 trochanter to femoral head centre were measured.

\section{$44 \quad$ Findings}

45 Although using greater trochanter as a reference demonstrated greater errors at the extremes, both

46 techniques resulted in errors of 7-8 $\mathrm{mm}$ with $20^{\circ}$ of both femoral external rotation and flexion.

\section{Interpretation}

48 Moderate degrees of femoral external rotation combined with flexion can result in unsatisfactory

49 errors when templating limb length. There should be greater focus and an agreed definition for

50 femoral height. There is a clinical need for a method with a lower error in determining true femoral

51 height and the level of neck resection.

52 Keywords: femoral height, preoperative planning, limb length, total hip arthroplasty 


\section{INTRODUCTION}

54 Part of the aim of total hip arthroplasty (THA) is to restore hip biomechanics. On the femoral side

55 along with femoral offset, femoral height makes a critical contribution, particularly in restoring limb

56 length $[1,2]$. Preoperative templating for THA is typically performed on an anteroposterior (AP)

57 pelvic X-ray with the restoration of femoral head centre (FHC) being a key goal on the femoral side

58 of the joint. This has two components in the coronal plane: (i) femoral offset and (ii) femoral height.

59 In the literature femoral offset as a term is well-established and is consistently defined as the

60 horizontal distance from the femoral anatomical axis to FHC [3]. Femoral height on the other hand,

61 which is the major determinant of postoperative limb length and arguably the greatest source of

62 error, is not instantly recognised as a term and does not have a consistent definition. When measuring

63 the femoral contribution to limb length on X-ray, it can be defined as the vertical distance between

64 FHC and the apex of lesser trochanter (LT) or the vertical distance between FHC and the tip of the

65 greater trochanter (GT) as shown in Figure 1. Most commonly during surgery, the level of neck resection is referenced from the superior limit of LT, which can be directly visualised. Alternatively, some surgeons will reference FHC from the tip of GT but this bony landmark can only be accurately located using a needle. Normally on a preoperative X-ray, both the apex of the LT and the tip of GT are sharply defined whereas the superior border of the LT, as during surgery, does not have a sharp

70 endpoint.

71 Again, concerning preoperative templating, there is a general awareness of the potential errors in

72 femoral offset and neck shaft angle measurement on the AP X-ray in the presence of femoral

73 external rotation and flexion [4,5]. However, there is less understanding of the impact of the

74 combination of femoral external rotation and flexion on the measurement of femoral height,

75 particularly whether the reference of GT or LT is more reliable [4]. These rotations during imaging

76 are common and error in measurement (the difference between true and apparent) can lead to 
misinterpretation of femoral anatomy and inappropriate surgical planning [5]. This in turn may affect decisions on implant choice, component placement and ultimately patient outcomes. The problem can be visualised in Figure 1 where the left femur shows a true AP (i.e. $0^{\circ}$ external and $0^{\circ}$ flexion).

80 When external rotation is combined with flexion, FHC incorrectly projects more proximally relative 81 to surrounding bony femoral anatomy.

82 Limb length discrepancy (LLD) alters postoperative biomechanics following THA and is a common 83 source of patient dissatisfaction as well as a frequent reason for litigation $[2,6,7]$. Specifically, limb 84 lengthening in contrast to limb shortening results in the greatest dissatisfaction and it is important to understand the aetiology [8]. Acetabular or hip centre, as with FHC, is determined by the height and

86 offset. The literature indicates that postoperatively, acetabular offset and height tend to be reduced 87 [9]; therefore, cup placement per se would normally lead to a modest decrease in limb length. When using a cementless cup, as was the case in $67.6 \%$ of THA surgeries in the UK National Joint Registry for 2018, it is technically difficult to increase acetabular height beyond that of its premorbid state

90 [10]. This means that any significant limb lengthening following THA is almost invariably caused by 91 an error in femoral height [11]. This, in turn, is caused by making the femoral neck resection too

92 high, resulting in a proud stem and an increase in femoral height.

93 Previous research suggests that a difference of $\geq 5 \mathrm{~mm}$ can be perceived by $74 \%$ of controls and 94 THA patients and $12.5 \mathrm{~mm}$ by $100 \%$ of subjects in a cohort of 73 individuals (Female: Male $-44: 29$, 95 mean [SD] age - 66 [8], mean [SD] BMI - 27.9 [4.9]) [12]. A range of negative outcomes has been 96 previously associated with limb length changes after THA including pain and dislocation [11]. More 97 recently, a study of 123 participants (Female: Male - 75:48, mean [SD] age - 68.5 [11.3], mean [SD]

$98 \mathrm{BMI}-28.6[5.2])$ found that an increase in femoral height that is insufficient to produce a 99 symptomatic LLD can still result in a poorer one year outcome [13]. It is therefore clear from the 100 literature that a much greater focus and recognition of femoral height is required both during 
templating and surgery. This study aims to quantify the magnitude of errors of FHC height

102 measurement as determined by either GT-FHC or LT-FHC when using an X-ray that is not a true AP

103 (i.e. external rotation and flexion are simultaneously present).

104 METHODS

105 Dataset of femoral shapes

106 The dataset of femoral shapes was produced using a statistical shape model, previously described [4],

107 to facilitate automated measurement of GT-FHC and LT-FHC. Segmented femurs (30 male, M, and 10842 female, F) from the Virtual Skeleton Database (SICAS, Swiss Institute for Computer-Assisted 109 Surgery, Switzerland) were used to build the statistical shape models in Scalismo (R0.12, Graphics 110 and Vision Research Group, University of Basel, Switzerland) [14,15]. Two models were built: one

111 using the male femoral shapes and the other using the female equivalent. The shape variation 112 described from the first 10 modes of the model equated to $96 \%$ for the males and $98 \%$ for the 113 females. A total of fifty shapes were then generated from each model $(n=100 ; M: F=50: 50)$ by 114 random generation of shape parameters; these values were drawn from a normal distribution and 115 were limited to \pm 3 standard deviations. Shapes generated using this method all have the same 116 number of points (approximately 19,000) with each point being in roughly the same anatomical 117 location across individuals. This key advantage allowed for measurement to be automated, without 118 which the analysis of combined rotations would not be feasible within a practical timeframe.

\section{Femoral orientation}

120 All shapes were put in a consistent neutral orientation by aligning the plane formed by three points:

121 (i) head centre, (ii) anatomical axis in the upper proximal region, and (iii) anatomical axis in the 122 lower proximal region. This was achieved in MATLAB (R2015b, The MathWorks, Inc., USA). Each 123 shape was also translated so the femoral head centre was at the origin (zero point in $\mathrm{X}, \mathrm{Y}$ and $\mathrm{Z}$ 
124 axes). Similar to a previous study, the shapes were then assigned an external rotation followed by

125 flexion [4]. The range for each rotation was from $0^{\circ}$ to $50^{\circ}$ in $10^{\circ}$ increments leading to a total of 36

126 distinct orientations being simulated.

127 Simulated $X$-rays

128 X-ray imaging of the femora in these orientations was then simulated in MATLAB using a

129 previously described algorithm $[16,17]$. The process involved joining a source point to each point on

130 the femur and then calculating the intersection with the X-ray detector plane (Figure 2). In line with

131 typical clinical practice, the source-image distance (SID) was $1.2 \mathrm{~m}[5,18]$. The FHC was offset from

132 the central beam by $90 \mathrm{~mm}$ (the approximate average distance from the midline of the body to the

133 FHC, reflecting the clinical practice of directing the central beam to the pubic symphysis) [9]. The

134 2D image was magnified by the ratio of SID to the source-object distance (SOD); since SOD is fixed

135 at a value of $1 \mathrm{~m}$, the magnification factor was 1.2 in all cases. Magnification correction was

136 performed for all measurements taken on each 2D image. The FHC in 2D was located using the

137 circle-fit function in MATLAB on the boundary points of the head region. To identify the tip of GT,

138 the head and neck points were excluded, and the remaining points were sorted by their Z-coordinate;

139 the largest value was the GT tip. The equation of the line perpendicular to the femoral shaft axis and

140 through the GT tip was then constructed and GT-FHC was calculated. If FHC was below GT, it was

141 assigned a negative sign and a positive sign if above. The tip of LT was identified by constructing a

142 line at the base of LT and finding the point on the LT perpendicular and furthest away from the

143 baseline. The distance (along the vertical axis of the image) to the FHC was then defined as LT-FHC

144 (Figure 1).

145 Statistical analysis

146 All statistical analysis was performed in the R statistical software environment [19]. Linear mixed-

147 effects models, as opposed to standard multivariate linear regression, were used for statistical 
148 analysis due to multiple measurements being made on the same shapes; the lme4 package was used

149 for model fitting [20]. Mixed-effects models combine fixed effects, that are assumed to affect only

150 the mean (e.g. rotation), and random effects that affect variability (e.g. due to unquantified subject-

151 specific differences). Separate models were fitted for LT-FHC error and GT-FHC error as the

152 dependent variables; in all cases the fixed effects were external rotation, flexion, their interaction,

153 and sex while the random effect was the femur ID (a dummy variable coded from 1-100). A squared

154 term (for both external rotation and flexion) was added as an independent variable given the

155 relationship was non-linear. The models allowed for a different intercept for each participant. The

156 MuMIn package [21] facilitated calculation of $\mathrm{R}^{2}$ values for both fixed effects (marginal $\mathrm{R}^{2}$, hereafter

157 denoted by $R_{m}^{2}$ ) and the overall model including random effects (conditional $\mathrm{R}^{2}$, hereafter denoted

158 by $R_{c}^{2}$ ). The R-squared value estimates the variance explained by the fixed effects (i.e. rotations and

159 sex) part of the model (in the case of $R_{m}^{2}$ ) and the variance explained by the model as a whole (i.e.

160 including fixed effects of rotations and sex as well as the random intercept) in the case of $R_{c}^{2}$. Table

1611 shows the coefficients of the fixed effects part of the model which represent the expected change in

162 measurement error for changes in external rotation, flexion, and sex. These coefficients were used to

163 produce predictions from the model and associated confidence intervals (Figure 3).

164 RESULTS

165 A large proportion of the variance in the GT-FHC measurement was explained by sex, external 166 rotation, flexion and subject-specific differences (Table $1 ; R_{c}^{2}=0.97$ ). The $R_{c}^{2}$ for the LT-FHC was

167 lower at 0.85 (Table 1). Interaction terms had a significant effect $(\mathrm{p}<0.001)$ on both measures

168 showing that combined rotations had a large influence on the preoperative planning measures. This

169 suggests the effect of each rotation on measurement cannot be assessed in isolation, e.g. the effect of

170 external rotation on GT-FHC is dependent on the degree of flexion. 
171 The error in GT-FHC was relatively unaffected by uniaxial rotation, i.e. where either flexion or

172 external rotation was kept neutral (Figure 3). In contrast, combined rotations led to significant errors

173 which were more severe at higher rotations. The trend for LT-FHC was more non-linear; error

174 increased up to $20^{\circ}$ but higher rotations led to less severe errors than with GT-FHC (Figure 3).

175 Figure 4 shows the measurements on the mean shape at different levels of rotation. The mean value

176 for GT-FHC at neutral orientation was $-12.2 \mathrm{~mm}$ (i.e. FHC was $12.2 \mathrm{~mm}$ below the tip of GT)

177 whereas the value at $50^{\circ}$ external and $50^{\circ}$ flexion was $17.0 \mathrm{~mm}$ (i.e. FHC was $17.0 \mathrm{~mm}$ above the tip

178 of GT): this represents an error of $29.2 \mathrm{~mm}$ at the extreme of the range of combined rotations. At

179 neutral orientation, the LT-FHC measure was $51.9 \mathrm{~mm}$. The largest error for LT-FHC was $10.0 \mathrm{~mm}$,

180 significantly lower than GT-FHC (Figure 3). However, if we look just at the more likely

181 combination of $20^{\circ}$ of external rotation and flexion, the error for GT-FHC was $8.1 \mathrm{~mm}$ and the error

182 for LT-FHC was $7.4 \mathrm{~mm}$ (Figure 5). The difference between the two techniques is now small and

183 these degrees of femoral external rotation and flexion would be expected to be more common than

184 the more extreme values. The error in GT-FHC was increased in male femoral shapes by $1.55 \mathrm{~mm}$

185 (95\% CI: 1.10-2.00) independent of rotation.

\section{DISCUSSION}

187 This study aimed to determine the magnitude of errors of femoral height measurement as determined

188 by either GT-FHC or LT-FHC when using an X-ray that is not a true AP (i.e. external rotation and

189 flexion occurring together). A simulation study was performed and an important link between

190 combined femoral external rotation and flexion, and error in FHC height measurement was

191 demonstrated. The GT-FHC measure was shown to have $29.2 \mathrm{~mm}$ of error with a combination of

192 external rotation and flexion of $50^{\circ}$ each whereas, under the same conditions, the largest error for

193 LT-FHC was much less at $10 \mathrm{~mm}$. However as can be appreciated from a clinical perspective, the

194 appearance of external rotation and flexion of $50^{\circ}$ as illustrated in the top right image of Figure 4 is 
rarely seen whereas the appearance of external rotation and flexion of $20^{\circ}$ as illustrated in Figure 5 is certainly not infrequent on a preoperative X-ray. In fact, in this projection, FHC is at the level of the

197 GT which many surgeons consider to be normal. Certainly, in this study, FHC was never above the

198 tip of GT when a femur was in neutral orientation. In the scenario of external rotation and flexion of $19920^{\circ}$ both techniques have errors of between 7 and $8 \mathrm{~mm}$, which, when combined with magnification 200 and intraoperative measurement errors, could approach $10 \mathrm{~mm}$ [22].

201 The placement of components in THA has a strong influence on the biomechanics of the restored 202 joint. Unfavourable reconstruction of hip geometry can lead to changes in muscle moment arms, 203 which change the amount of force production required for movement [23]. Limb length

204 discrepancies in THA patients are associated with reduced gait velocity and contact forces 205 postoperatively [2]. The vast majority of individuals can detect a difference in limb length of $10 \mathrm{~mm}$ 206 and therefore during surgery the surgeon should aim to restore limb length with discrepancies less 207 than $10 \mathrm{~mm}$ [12]. However, the evidence from this study suggests that this level of accuracy can be 208 challenging with many preoperative X-rays. Thus, there is a need for both a greater focus and 209 understanding of femoral height during THA. At present the term femoral height does not have an 210 agreed definition. At times there can be new bone formation around the tip of the GT, whereas loss 211 of definition around the LT is very uncommon. We, therefore, propose that femoral height would be 212 best defined as: the distance from FHC to the apex of the LT along the vertical axis of the image.

213 In conclusion, moderate degrees of femoral external rotation, when combined with flexion can result 214 in unsatisfactory errors when templating limb length. Use of lesser trochanter as a reference (as 215 opposed to greater trochanter) may lead to lower error in measurement of femoral height, particularly 216 at high external rotation and flexion. At low/moderate combined external rotation and flexion, both 217 methods had an error of $7-8 \mathrm{~mm}$. There is a need to either improve the quality of preoperative X218 rays, use other modalities such as CT, or find better ways of determining the level of neck resection 
219 intraoperatively to restore FHC. There is also a need for more emphasis on femoral height and an 220 agreed definition.

\section{Funding}

222 This work was funded by the Belfast Arthroplasty Research Trust (http://www.bartni.org/).

\section{Conflict of interest}

224 David Beverland has received funding from DePuy Synthes and Zimmer Biomet but not directly for 225 this work.

\section{Ethical approval}

227 Anonymised imaging data was provided under a creative commons license (CC BY-NC-SA) by the

228 Swiss Medical Image Repository. Data acquisition was fully anonymised and controlled by a 229 governmental data protection agency (Datenschutzbeauftragter Stadt Bremen, Bremen, Germany).

\section{Acknowledgments}

231 Author contributions: 1) Study concept and design - JOC, JH, DEB, ND, AL; 2) Acquisition of data 232 - JOC, AL; 3) Analysis and interpretation of data - JOC, JH, DEB, ND, AL; 4) Drafting of the 233 manuscript - JOC, JH, DEB, ND, AL; 5) Critical revision of the manuscript for important 234 intellectual content - JOC, JH, DEB, ND, AL 
236 [1] Bolink SAAN, Lenguerrand E, Brunton LR, Hinds N, Wylde V, Heyligers IC, et al. The

[2] Li J, McWilliams AB, Jin Z, Fisher J, Stone MH, Redmond AC, et al. Unilateral total hip

[6] Hofmann AA, Skrzynski MC. Leg-length inequality and nerve palsy in total hip arthroplasty: a lawyer awaits! Orthopedics 2000;23:943-4.

[3] Lecerf G, Fessy MH, Philippot R, Massin P, Giraud F, Flecher X, et al. Femoral offset: Anatomical concept, definition, assessment, implications for preoperative templating and hip arthroplasty. Orthop Traumatol Surg Res 2009;95:210-9.

[4] O'Connor JD, Rutherford M, Hill JCC, Beverland DEE, Dunne NJJ, Lennon ABB, et al. Effect of combined flexion and external rotation on measurements of the proximal femur from anteroposterior pelvic radiographs. Orthop Traumatol Surg Res 2018;104:449-54.

[5] Lechler P, Frink M, Gulati A, Murray D, Renkawitz T, Bücking B, et al. The influence of hip rotation on femoral offset in plain radiographs. Acta Orthop 2014;85:389-95.

Desai AS, Dramis A, Board TN. Leg length discrepancy after total hip arthroplasty: a review of literature. Curr Rev Musculoskelet Med 2013;6:336-41.

[8] Ranawat CS, Rao RR, Rodriguez JA, Bhende HS. Correction of limb-length inequality during total hip arthroplasty. J Arthroplasty 2001;16:715-20.

[9] Meermans G, Van Doorn J, Kats JJ. Restoration of the centre of rotation in primary total hip arthroplasty the influence of acetabular floor depth and reaming technique. Bone Jt J 2016;98B:1597-603.

261 [11] Konyves A, Bannister GC. The importance of leg length discrepancy after total hip arthroplasty. 
[12] Sykes A, Hill J, Orr J, Humphreys P, Rooney A, Morrow E, et al. Patients' perception of leg length discrepancy post total hip arthroplasty. Hip Int 2015;25:452-6.

[13] Warnock JM, Karayiannis PN, Gallagher NE, Hill JC, Beverland DE. Are There Gender-

[14] Kistler M, Bonaretti S, Pfahrer M, Niklaus R, Büchler P. The Virtual Skeleton Database: An Open Access Repository for Biomedical Research and Collaboration. J Med Internet Res 2013;15:e245.

[15] Clogenson M, Duff JM, Luethi M, Levivier M, Meuli R, Baur C, et al. A statistical shape model of the human second cervical vertebra. Int J Comput Assist Radiol Surg 2014;10:1097-107.

[16] O'Connor J, Rutherford M, Hill J, Beverland D, Dunne N, Lennon A. Statistical Shape Model Based 2D--3D Reconstruction of the Proximal Femur---Influence of Radiographic Femoral Orientation on Reconstruction Accuracy. In: Gefen A, Weihs D, editors. Comput. Methods Biomech. Biomed. Eng. Proc. 14th Int. Symp. C. Tel Aviv, Isr. 2016, Cham: Springer International Publishing; 2018, p. 153-60.

[17] Freud N, Duvauchelle P, Létang JM, Babot D. Fast and robust ray casting algorithms for virtual X-ray imaging. Nucl Instruments Methods Phys Res Sect B Beam Interact with Mater Atoms 2006;248:175-80.

[18] Merle C, Waldstein W, Pegg E, Streit MR, Gotterbarm T, Aldinger PR, et al. Femoral offset is underestimated on anteroposterior radiographs of the pelvis but accurately assessed on anteroposterior radiographs of the hip. J Bone Joint Surg Br 2012;94:477-82.

[19] R Core Team. R: A Language and Environment for Statistical Computing, R Foundation for Statistical Computing, Vienna, Austria. 2017:https://www.r-project.org/.

[20] Bates D, Mächler M, Bolker B, Walker S. Fitting Linear Mixed-Effects Models Using lme4. J Stat Softw 2015;67:1-48.

[21] Barton K. MuMIn: Multi-Model Inference 2016:https://cran.r-project.org/package=MuMIn. 
289 [22] King RJ, Makrides P, Gill JA, Karthikeyan S, Krikler SJ, Griffin DR. A novel method of 290 accurately calculating the radiological magnification of the hip. J Bone Jt SurgeryBritish Vol $291 \quad 2009 ; 91: 1217-22$.

292 [23] Bonnin MP, Archbold PHA, Basiglini L, Selmi TA, Beverland DE. Should the acetabular cup 293 be medialised in total hip arthroplasty? HIP Int 2011;21:428-35. 
296 Table 1: Results of statistical analyses showing unstandardised coefficients $(B)$ of the fixed parts of the mixed effects models, 95\% confidence intervals $297(C I)$, p-value $(p)$, marginal $R_{m}^{2}$, and conditional $R_{c}^{2}$. Female was the reference level for gender and, as such, "Sex (male)" is only included for male subjects. 298 The R-squared value estimates the variance explained by the fixed effects (i.e. rotations and sex) part of the model (in the case of $R_{m}^{2}$ ) and the variance 299 explained by the model as a whole (i.e. including fixed effects of rotations and sex as well as the random intercept) in the case of $R_{c}^{2}$. The coefficients of 300 the fixed effects part of the model represent the expected change in measurement error for changes in external rotation, flexion, and sex. The Flexion ${ }^{2}$ and 301 External $^{2}$ terms model the non-linear changes. The Flexion: External parameter defines the dependence of measurement error on the interaction between 302 the two rotational axes.

\begin{tabular}{|c|c|c|c|c|c|c|}
\hline & \multicolumn{3}{|c|}{ LT-FHC error } & \multicolumn{3}{|c|}{ GT-FHC error } \\
\hline & $B$ & CI & $p$ & $B$ & CI & $p$ \\
\hline Intercept & -0.64 & $-1.10--0.18$ & 0.007 & -1.33 & $-1.68--0.98$ & $<0.001$ \\
\hline Flexion & 0.37 & $0.36-0.38$ & $<0.001$ & 0.22 & $0.21-0.23$ & $<0.001$ \\
\hline Flexion $^{2}$ & -0.007 & $-0.0070--0.0066$ & $<0.001$ & -0.0038 & $-0.0040--0.0037$ & $<0.001$ \\
\hline External & 0.15 & $0.14-0.16$ & $<0.001$ & 0.10 & $0.09-0.11$ & $<0.001$ \\
\hline External $^{2}$ & -0.0027 & $-0.0029--0.0025$ & $<0.001$ & -0.0014 & $-0.0016--0.0012$ & $<0.001$ \\
\hline $\begin{array}{l}\text { Flexion: } \\
\text { External }\end{array}$ & 0.0031 & $0.0029-0.0033$ & $<0.001$ & 0.0111 & $0.0110-0.0113$ & $<0.001$ \\
\hline Sex (male) & 0.48 & $-0.12-1.09$ & 0.12 & 1.55 & $1.10-2.00$ & $<0.001$ \\
\hline$R_{m}^{2}$ & & 0.69 & & & 0.96 & \\
\hline$R_{c}^{2}$ & & 0.85 & & & 0.97 & \\
\hline
\end{tabular}



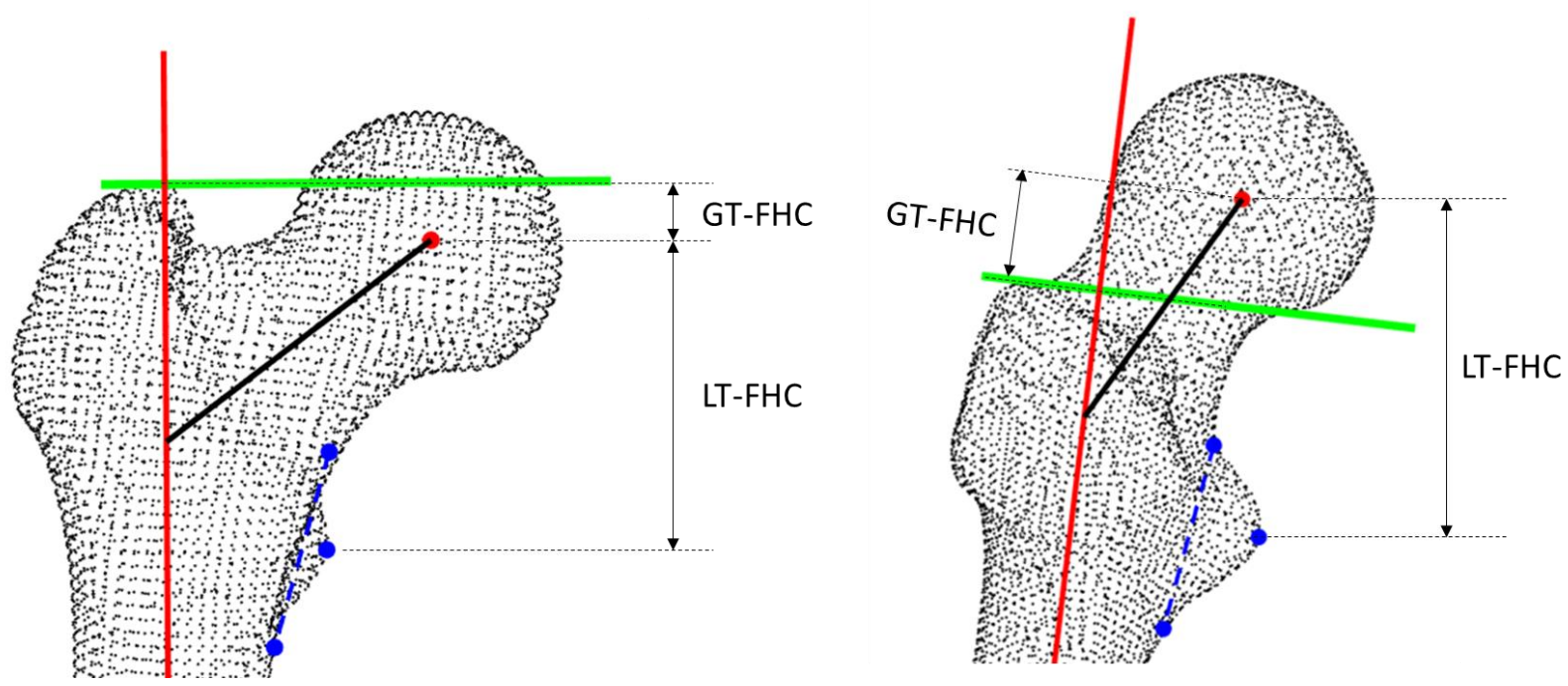

Figure 1. Measurement of femoral head height using greater trochanter (GT-FHC) and lesser trochanter (LT-FHC) as a reference. The femur is in neutral orientation on the left while the femur on the right is in an externally rotated and flexed orientation. The GTFHC measurement is parallel to femoral axis while the LT-FHC is along the vertical axis of the image. 


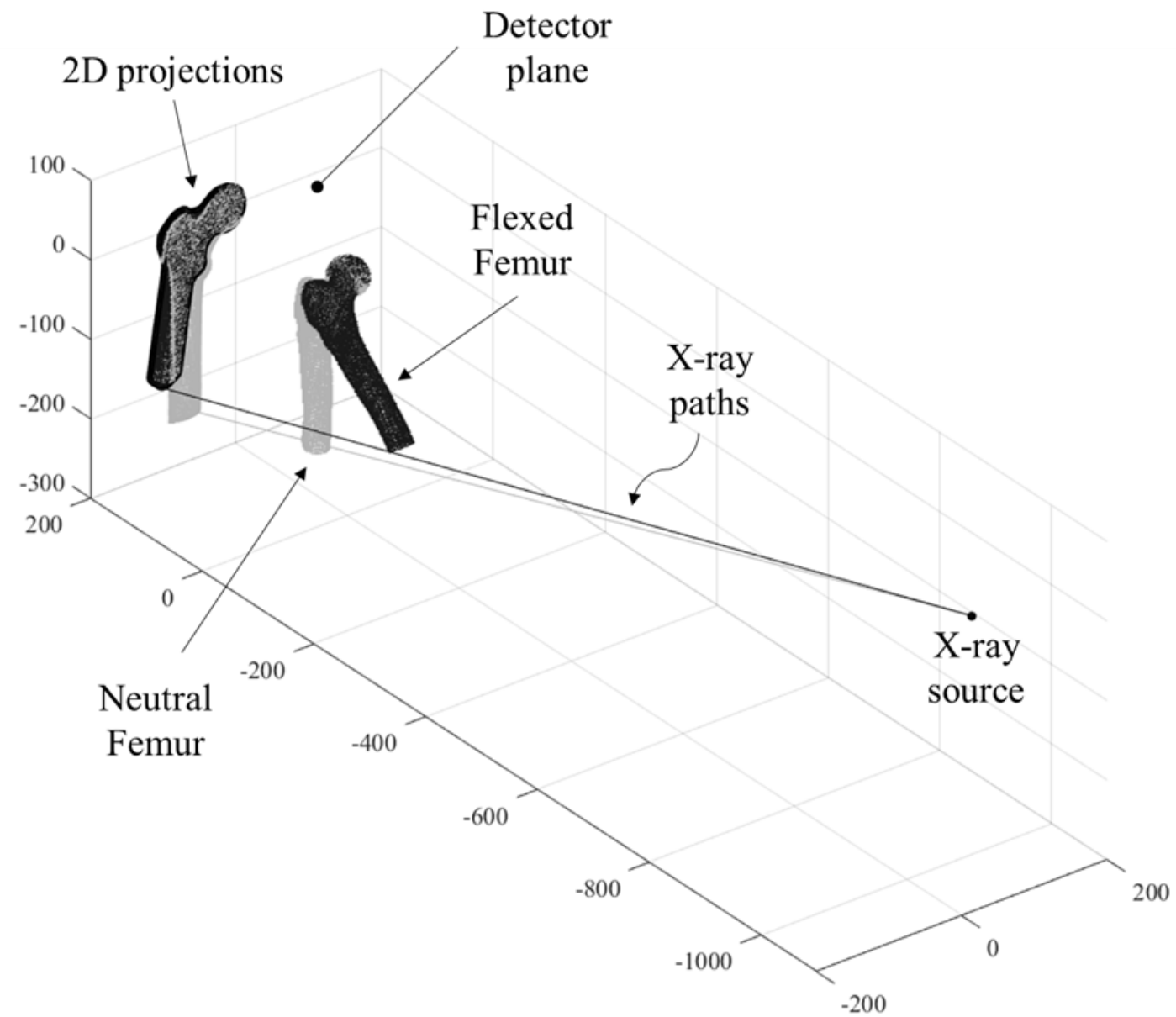

Figure 2. Simulated X-ray imaging setup. 


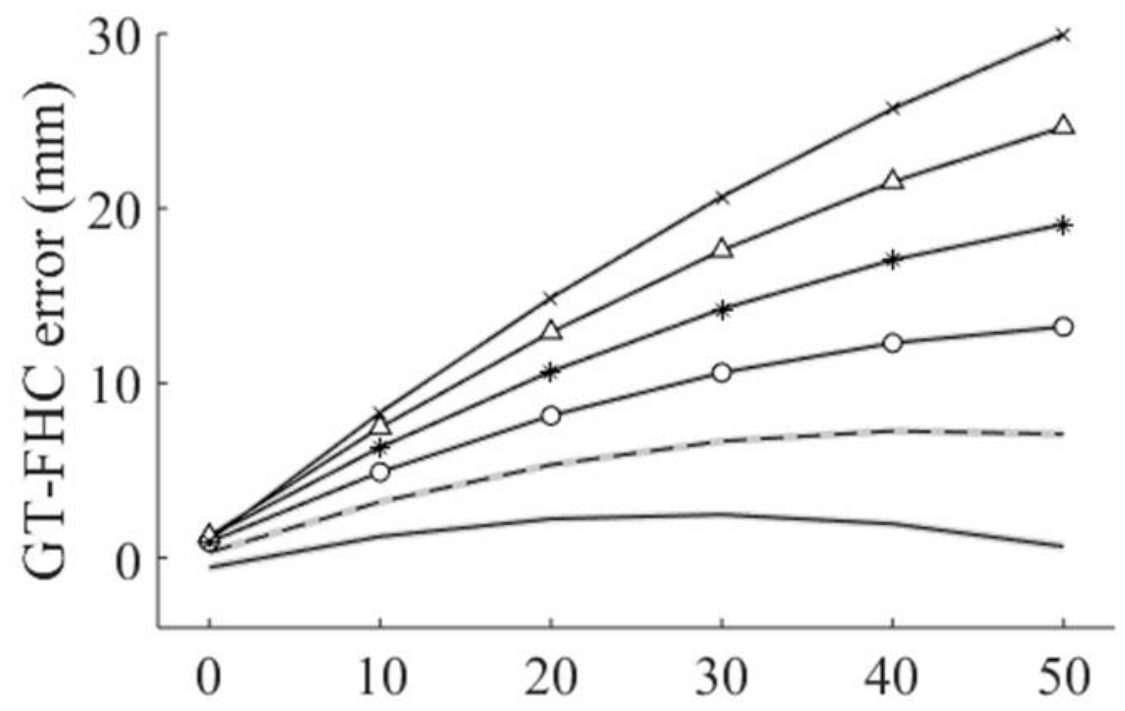

External

Rotation

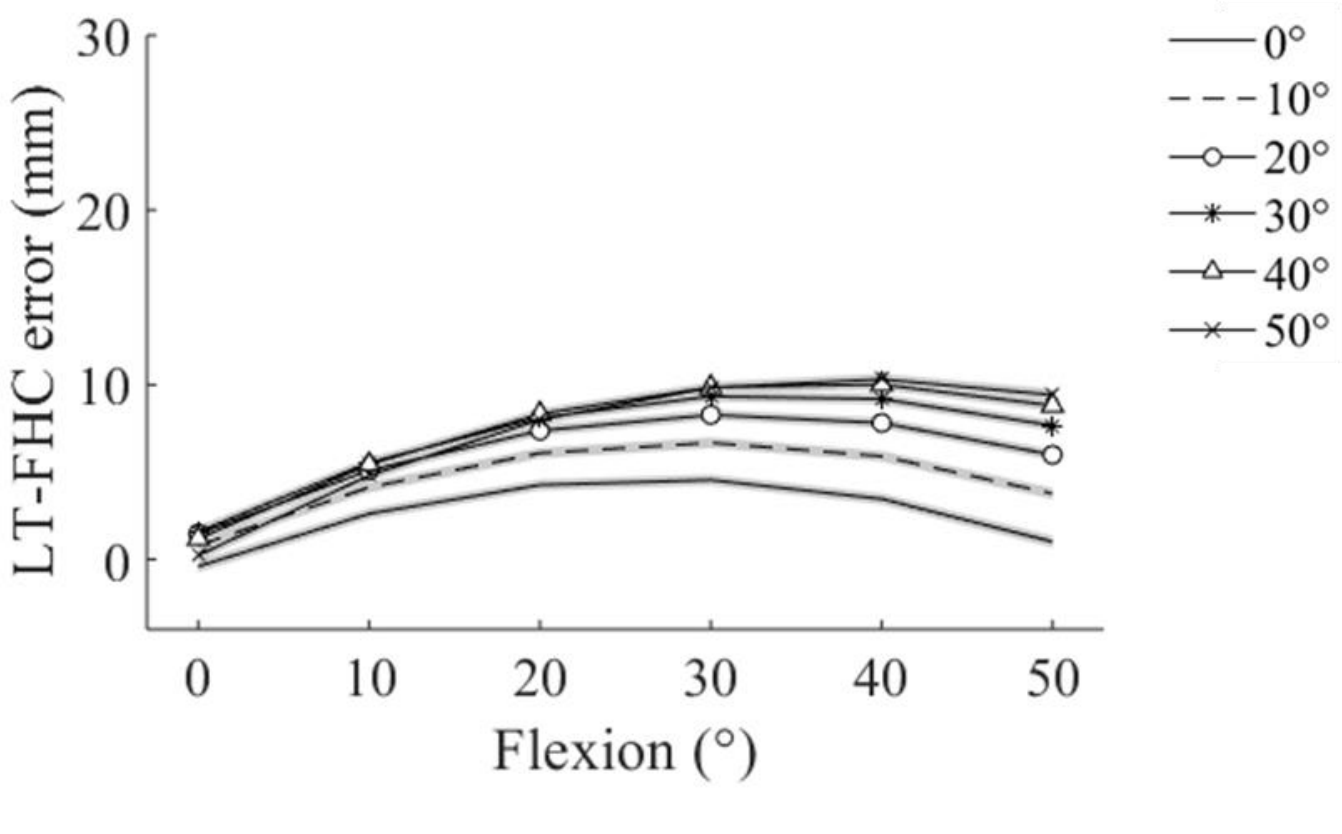

311 Figure 3: Interaction plots showing the relationship between flexion and the predicted value (95\% 312 confidence interval) of the fitted models for GT-FHC and LT-FHC at different levels of external 313 rotation. 


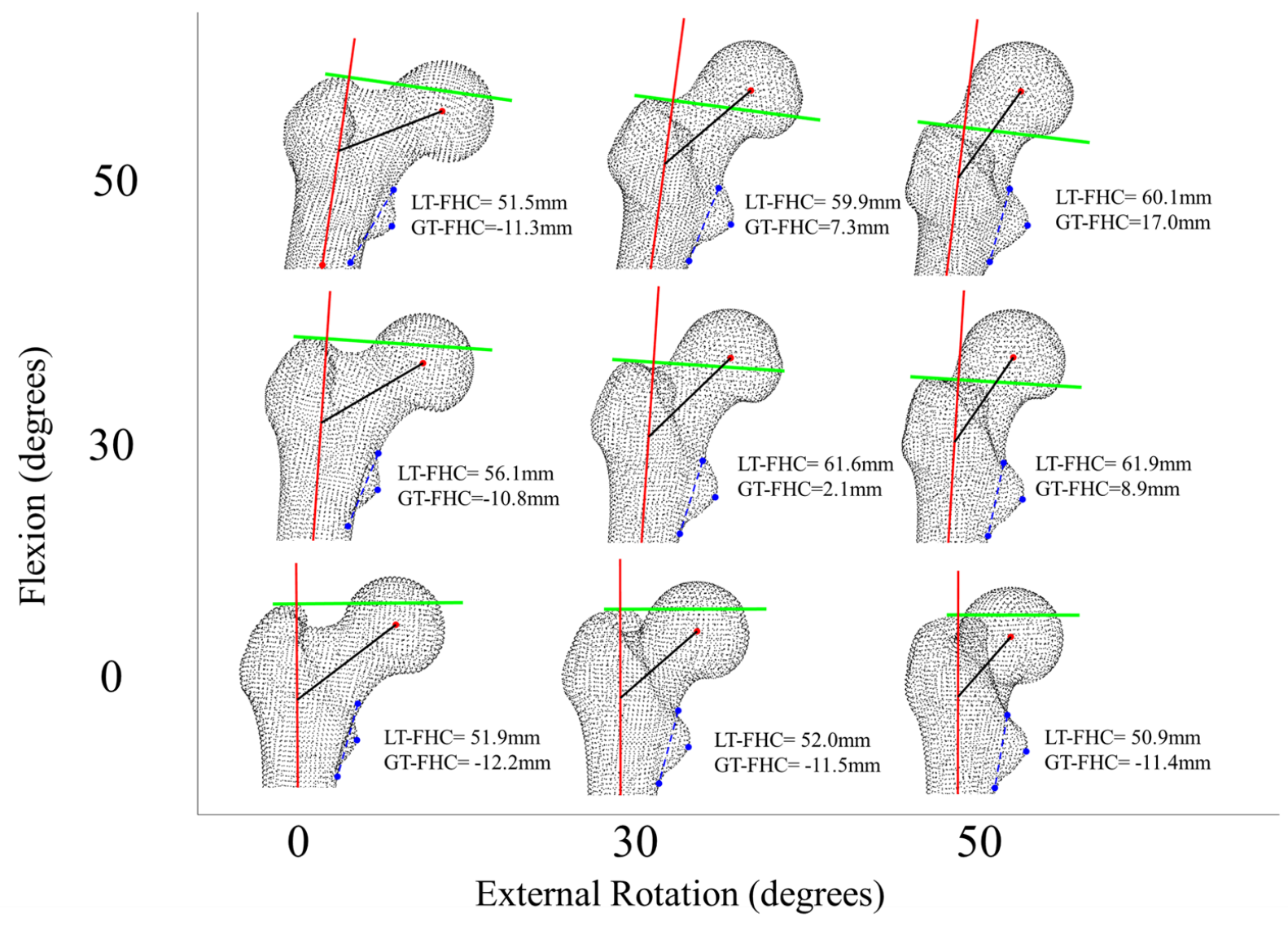

315 Figure 4: Representative 2D projections of the proximal femur varying in both external rotation and 316 flexion. 


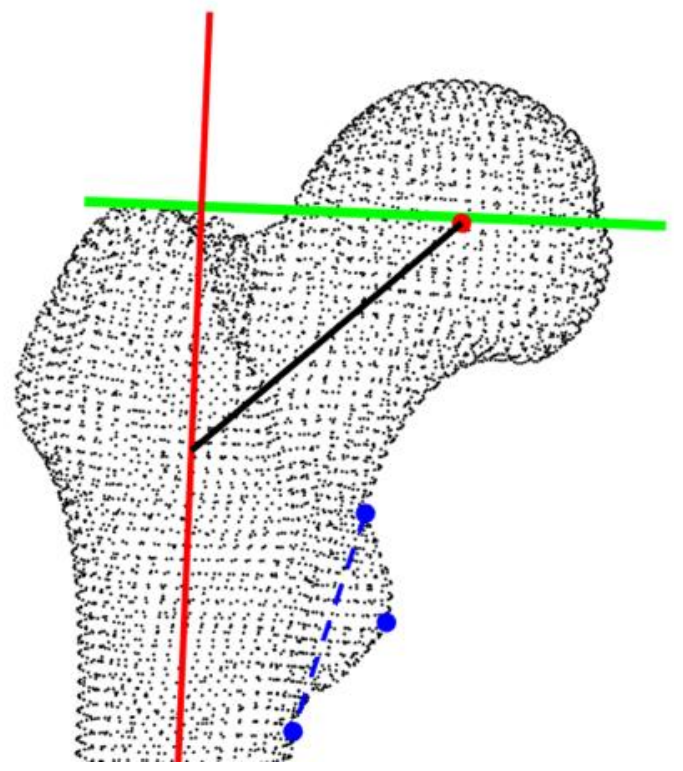

319 Figure 5. Projection of femur in $20^{\circ}$ external rotation and $20^{\circ}$ flexion. The error values for this 320 orientation are similar on average at $8.1 \mathrm{~mm}$ for GT-FHC and $7.4 \mathrm{~mm}$ for LT-FHC. 


\section{Conflict of interest statement}

David Beverland has received funding from Depuy Synthes and Zimmer Biomet but not directly for this study. Other authors report no conflicts of interest regarding this work. 